\title{
Half-Bridge Zero Voltage Switching Converter with Three Resonant Tanks
}

\author{
Bor-Ren Lin ${ }^{\dagger}$ and Wei-Jie Lin* \\ $\dagger^{*}$ Dept. of Electrical Eng., National Yunlin University of Science and Technology, Yunlin, Taiwan
}

\begin{abstract}
This paper presents a zero voltage switching (ZVS) converter with three resonant tanks. The main advantages of the proposed converter are its ability to reduce the switching losses on the power semiconductors, decrease the current stress of the passive components at the primary side, and reduce the transformer secondary windings. Three resonant converters with the same power switches are adopted at the low voltage side to reduce the current rating on the transformer windings. Using a series-connection of the transformer secondary windings, the primary side currents of the three resonant circuits are balanced to share the load power. As a result, the size of both the transformer core and the bobbin are reduced. Based on the circuit characteristics of the resonant converter, the power switches are turned on at ZVS. The rectifier diodes can be turned off at zero current switching (ZCS) if the switching frequency is less than the series resonant frequency. Therefore, the reverse recovery losses on the rectifier diodes are overcome. Experiments with a $1.6 \mathrm{~kW}$ prototype are presented to verify the effectiveness of the proposed converter.
\end{abstract}

Key words: DC/DC converter, PWM, Resonant converter

\section{INTRODUCTION}

High efficiency power converters have drawn a great deal of attention for use in modern power electronic applications such as renewable energy conversion systems, Photovoltaic (PV) inverter systems, industry power conversion systems and personal commercial power units. To meet the efficiency requirements of the Environment Protection Agency (EPA) and the Climate Savers Computing Initiatives (CSCI) for modern power supply units, soft switching converters are generally adopted. Zero voltage switching (ZVS) techniques such as active clamp techniques and full-bridge phase shift pulse-width modulation (PWM), have proposed to reduce the switching losses of MOSFETs. However, the ZVS ranges of these techniques are limited to specific input voltage ranges or load conditions. Series resonant converters and parallel resonant converters have proposed in [1], [2]. They exhibit both high efficiency and low noise. However, the output voltage cannot be properly regulated at the no-load condition in conventional series resonant converters. The LLC series

Manuscript received Dec. 29, 2013; accepted May 26, 2014

Recommended for publication by Associate Editor Dehong Xu.

${ }^{\dagger}$ Corresponding Author: linbr@yuntech.edu.tw

Tel: +886-5-5516128 ext. 4259, Fax: +886-05-342601, YunTech

*Dept. of Electrical Eng., National Yunlin University of Science and Technology, Taiwan resonant converters in [3]-[11] have been proposed with the advantages of high voltage gain, high conversion efficiency and high power density. All of the power switches can be turned on at ZVS. If the operating switching frequency is lower than the series resonant frequency, the rectifier diodes can be turned off at zero current switching (ZCS). As a result, the reverse recovery losses for the rectifier diodes are reduced.

This paper presents a new resonant converter with three series resonant circuits and a full-wave diode rectifier to achieve soft switching for all of the power switches. Due to the resonant behavior, the power switches can be turned on under ZVS with wide input voltage ranges and load conditions. If the operating switching frequency is lower than the series resonant frequency, the rectifier diodes can be turned off under ZCS. Therefore, the switching losses of the power switches and the reverse recovery problem of the rectifier diodes can be improved. Three resonant circuits with the same power switches are adopted in order to reduce the size of the magnetic cores and the current stress on the primary windings. The secondary windings of two transformers are connected in series in order to balance the primary currents and to share the input current. Finally, the design procedure and test results obtained with a $1.6 \mathrm{~kW}$ prototype are provided to verify the effectiveness of the proposed converter. 


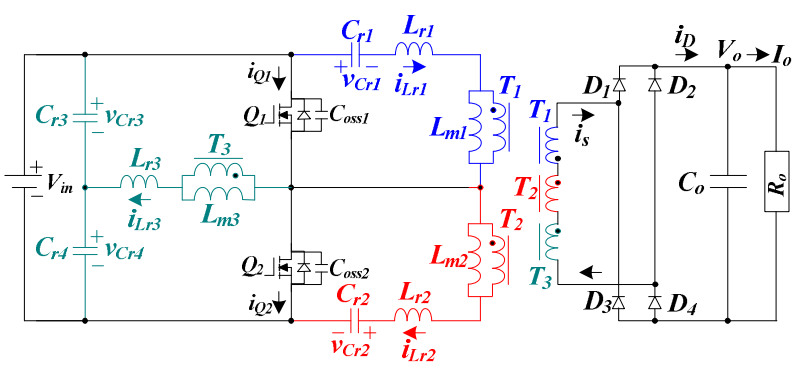

Fig. 1. Circuit configuration of proposed resonant converter.

\section{CirCUIT CONFIGURATION}

A conventional LLC with a half-bridge converter can be adopted in renewable energy DC/DC converters. Basically the output voltage of a renewable energy source is low voltage. As a result, the input voltage of the LLC converter is a low voltage such as $24 \mathrm{~V}-48 \mathrm{~V}$, and the output voltage of the LLC is a high voltage such as $400 \mathrm{~V}$. In order to reduce the input current stress of the LLC converter, a parallel connection of several LLC converters can be adopted. However, more power switches are needed in this parallel LLC topology. Fig. 1 gives the circuit configuration of the proposed converter with the ZVS/ZCS feature. The proposed converter is controlled by using the frequency modulation technique to regulate the output terminal voltage under input voltage and load current variations. Three resonant tanks with the same power switches are adopted in the proposed converter. The three resonant circuits have the same power switches $Q_{1}$ and $Q_{2}$ and secondary side components $D_{1}-D_{4}$ and $C_{o}$. The first resonant tank includes $C_{r 1}, L_{r 1}$ and $L_{m 1}$. The components of the second resonant tank are $C_{r 2}, L_{r 2}$ and $L_{m 2}$. The third resonant tank includes $C_{r 3}, C_{r 4}, L_{r 3}$ and $L_{m 3}$. Each resonant tank transfers one-third of the power to the output load. As a result, the current ratings of the resonant inductors, resonant capacitors and transformers are reduced. In order to balance the primary side currents of the three resonant tanks, the secondary windings of $T_{1}-T_{3}$ are connected in series. $V_{\text {in }}$ and $V_{o}$ are the input and output side voltages, the power switches $Q_{1}$ and $Q_{2}$ make up a half-bridge network, $\left(C_{r 1}, L_{r 1}\right.$ and $\left.L_{m 1}\right),\left(C_{r 2}, L_{r 2}\right.$ and $\left.L_{m 2}\right)$ and $\left(C_{r 3}, C_{r 4}, L_{r 3}\right.$ and $\left.L_{m 3}\right)$ make up the three resonant tanks. $T_{1}-T_{3}$ are the three isolation transformers. $D_{I}-D_{4}$ are the rectifier diodes. $C_{\text {oss } 1}$ and $C_{\text {oss } 2}$ are the output capacitances of $Q_{1}$ and $Q_{2}$, respectively. $C_{o}$ is the output capacitance. Based on the resonant behaviors, the power switches $Q_{1}$ and $Q_{2}$ are turned on under ZVS within all of the load ranges. If the switching frequency is lower than the series resonant frequency at the full load and maximum input voltage condition, the rectifier diodes $D_{1}-D_{4}$ can be turned off under ZCS. Therefore, the reverse recovery losses on the rectifier diodes are improved. General fast reverse recovery diodes instead of ultra-fast reverse recovery diodes can be adopted at the output side.

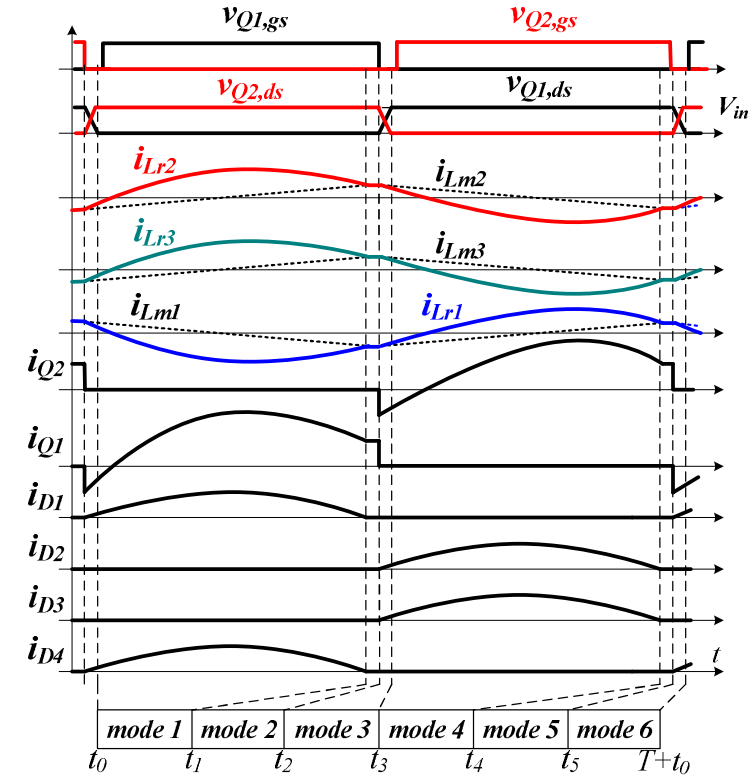

Fig. 2. Key waveforms of the proposed converter.

\section{OPERATION PRINCIPLE}

Before discussing the proposed converter, the following assumptions are made to simplify the system analysis. The transformers $T_{1}-T_{3}$ are identical with the same magnetizing inductances $L_{m 1}=L_{m 2}=L_{m 3}=L_{m}$ and turns ratio $n=n_{p} / n_{s}$. The power switches have the same output capacitances $C_{\text {oss } 1}=C_{\text {oss } 2}=C_{\text {oss. }}$. The four resonant capacitances are $C_{r 1}=C_{r 2}=2 C_{r 3}=2 C_{r 4}=C_{r}$. The three series resonant inductances are identical $L_{r 1}=L_{r 2}=L_{r 3}=L_{r}$. A frequency modulation scheme is adopted to regulate output voltage at the desired voltage level. If the switching frequency is greater than the series resonant frequency, there are four operation modes during one switching cycle. However, there are six operation modes in a switching cycle if the switching frequency is less than the series resonant frequency. Since the switching frequency of the proposed converter at full load is designed to be less than the series resonant frequency, there are six operating modes in the proposed converter. The key waveforms of the proposed converter in a switching cycle are given in Fig. 2, and the equivalent circuits of the proposed converter at different operation modes are shown in Fig. 3. Before time $t_{0}, Q_{1}$ and $Q_{2}$ are both turned off. The drain voltage $v_{Q 1, d s}$ decreases, the drain voltage $v_{Q 2, d s}$ increases and $D_{1}$ and $D_{4}$ are both conducting.

Mode $1\left[t_{0} \leq t<t_{l}\right]$ : At $t_{0}$, the drain voltage $v_{Q 1, d s}$ is decreased to zero voltage, and the drain voltage $v_{Q 2, d s}$ is increased to the input voltage $V_{i n}$. Since $i_{Q 1}$ is negative, the anti-parallel diode of $Q_{1}$ is conducting. Before $i_{Q 1}$ is positive, $Q_{1}$ can be turned on at this moment to achieve ZVS. In this mode, diodes $D_{1}$ and $D_{4}$ are conducting so that the secondary winding voltages $v_{T 2, s}=v_{T 3, s}=V_{o} / 3$ and $v_{T 1, s}=-V_{o} / 3$. As a result, the magnetizing voltages $v_{L m 2}=v_{L m 3}=n V_{o} / 3$ and $v_{L m 1}=-n V_{o} / 3$. The magnetizing current $i_{L m 1}$ decreases linearly with the slope of $-n V_{o} /\left(3 L_{m}\right)$, 
and the magnetizing currents $i_{L m 2}$ and $i_{L m 3}$ both increase linearly with the slope of $n V_{o} /\left(3 L_{m}\right) . L_{r 1}$ and $C_{r 1}$ in resonant tank 1 are resonant with the applied voltage $n V_{o} / 3 . L_{r 2}$ and $C_{r 2}$ in resonant tank 2 are resonant with the applied voltage $V_{i n}{ }^{-} n V_{o} / 3$. In the same manner, $C_{r 3}, C_{r 4}$ and $L_{r 3}$ are resonant in circuit 3 with the applied voltage $V_{i n} / 2-n V_{o} / 3$. The resonant frequency in the three resonant circuits is equal to $f_{r}=1 / 2 \pi \sqrt{L_{r} C_{r}}$. Power is delivered from the input terminal voltage $V_{i n}$ to the output load through resonant circuits 2 and 3. In resonant circuit 1, the energy stored in $L_{r 1}$ and $C_{r 1}$ is transferred to the output load through $Q_{1}, C_{r 1}, L_{r 1}$, $T_{1}, D_{1}$ and $D_{4}$. Since the switching frequency is less than the series resonant frequency in the proposed converter, the secondary winding current will be decreased to zero before switch $Q_{1}$ is turned off. This mode ends at time $t_{1}$ when the secondary side current $i_{s}=0$.

Mode $2\left[t_{1} \leq t<t_{2}\right]$ : At time $t_{1}, i_{L m 1}=i_{L r 1}, i_{L m 2}=i_{L r 2}$ and $i_{L m 3}=i_{L r 3}$. As a result, the secondary winding current is equal to zero and $D_{l}$ and $D_{4}$ are off. In this mode, switch $Q_{1}$ is still in the on-state. Therefore, $C_{r 1}, L_{r 1}$ and $L_{m 1}$ are resonant in circuit 1; $C_{r 2}, L_{r 2}$ and $L_{m 2}$ are resonant in circuit 2; and $C_{r 3}, C_{r 4}, L_{r 3}$ and $L_{m 3}$ are resonant in circuit 3 . The resonant frequency in this mode is equal to $f_{p}=1 / 2 \pi \sqrt{\left(L_{r}+L_{m}\right) C_{r}}$.

Mode $3\left[t_{2} \leq t<t_{3}\right]$ : At $t_{2}, Q_{1}$ is turned off. In this mode, $D_{2}$ and $D_{3}$ are conducting so that the primary winding voltages $v_{L m 1}=n V_{o} / 3$ and $v_{L m 2}=v_{L m 3}=-n V_{o} / 3$. The magnetizing current $i_{L m 1}$ increases with the slope of $n V_{o} /\left(3 L_{m}\right)$ and $i_{L m 2}$ and $i_{L m 3}$ both decrease with the slope of $-n V_{o} /\left(3 L_{m}\right)$. Since the inductor current $i_{L r 1}$ at time $t_{2}$ is negative, and $i_{L r 2}$ and $i_{L r 3}$ at time $t_{2}$ are positive, the current $i_{L r 2}+i_{L r 3}-i_{L r 1}$ charges $C_{o s s 1}$ and discharges $C_{o s s 2}$. If the energy stored in $L_{r 1}-L_{r 3}$ is greater than the energy stored in $C_{o s s 1}$ and $C_{o s s 2}$, then $C_{o s s 2}$ can be discharged to zero voltage. Since $C_{o s s}<<C_{r 1}-C_{r 4}$, the drain to source voltages of $Q_{1}$ and $Q_{2}$ are approximately equal to:

$$
\begin{gathered}
v_{Q 1, d s}(t) \approx \frac{i_{L r 2}\left(t_{2}\right)+i_{L r 3}\left(t_{2}\right)-i_{L r 1}\left(t_{2}\right)}{2 C_{o s s}}\left(t-t_{2}\right) \\
v_{Q 2, d s}(t) \approx V_{i n}-\frac{i_{L r 2}\left(t_{2}\right)+i_{L r 3}\left(t_{2}\right)-i_{L r 1}\left(t_{2}\right)}{2 C_{o s s}}\left(t-t_{2}\right)
\end{gathered}
$$

Mode $4\left[t_{3} \leq t<t_{4}\right]$ : At $t_{3}$, the drain voltage $v_{Q 1, d s}$ decreases to zero and the anti-parallel diode of $Q_{2}$ is forward biased. Before $i_{Q 2}$ becomes positive, $Q_{2}$ must be turned on to achieve ZVS. Since $D_{2}$ and $D_{3}$ are conducting in this mode, the magnetizing voltages $v_{L m 1}=n V_{o} / 3$ and $v_{L m 2}=v_{L m 3}=-n V_{o} / 3$. The magnetizing current $i_{L m 1}$ increases, and $i_{L m 2}$ and $i_{L m 3}$ decrease. In resonant circuit $1, V_{i n}-n V_{o} / 3$ is applied to the resonant components $L_{r 1}$ and $C_{r 1}$. In resonant circuit 2, voltage $n V_{o} / 3$ is applied to the resonant components $L_{r 2}$ and $C_{r 2}$. In the same manner, $L_{r 3}, C_{r 3}$ and $C_{r 4}$ in resonant circuit 3 are resonant with the applied voltage $V_{i n} / 2-n V_{o} / 3$. Power is delivered from the input terminal voltage $V_{\text {in }}$ to the output load through resonant circuits 1 and 3 . In resonant circuit 2,
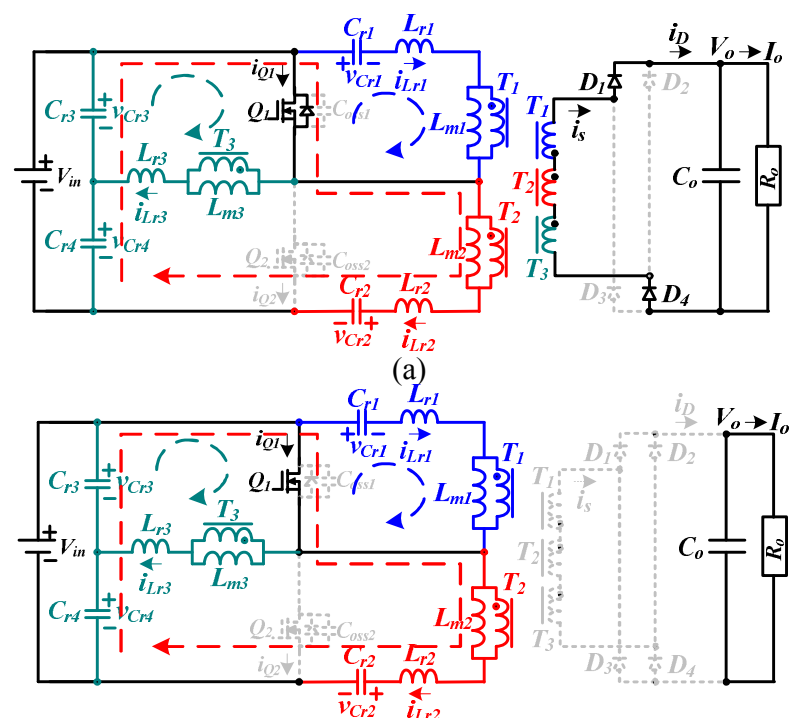

(b)

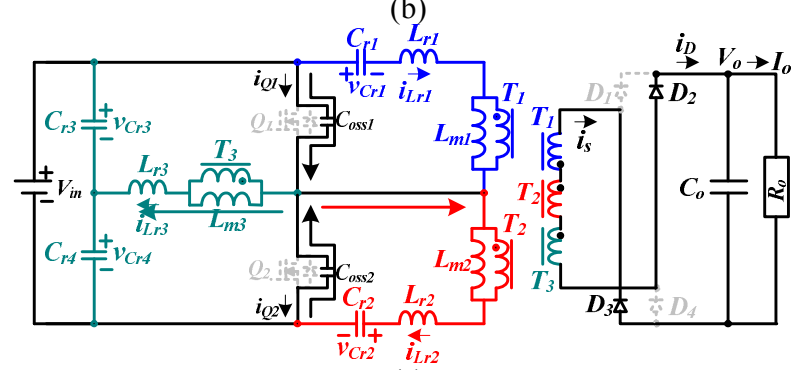

(c)

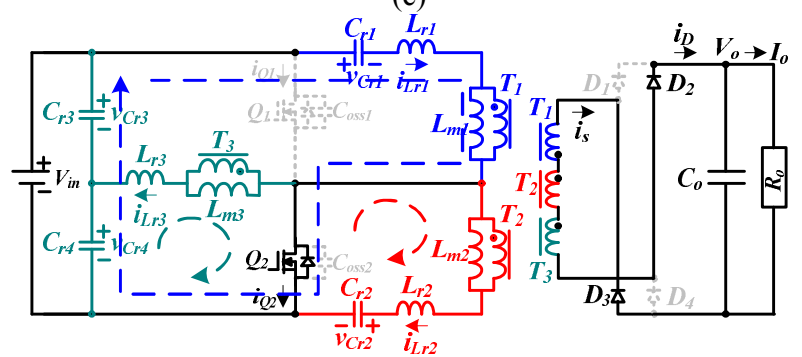

(d)

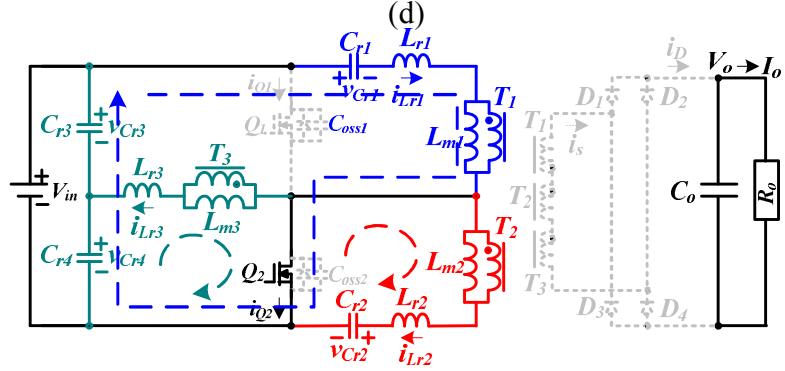

(e)

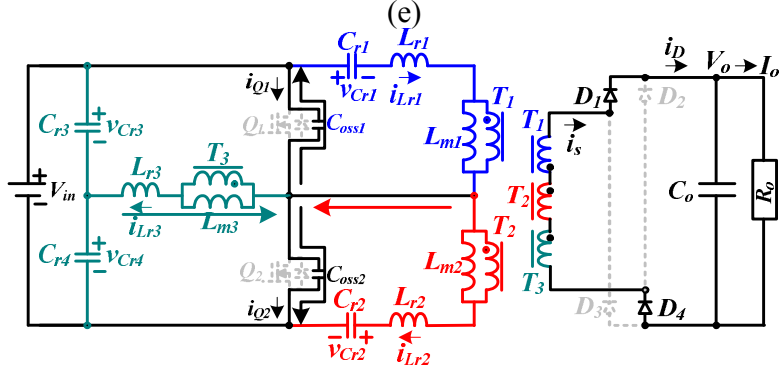

(f)

Fig. 3. Equivalent circuits of the proposed converter at different operation modes. (a) Mode 1. (b) Mode 2. (c) Mode 3. (d) Mode 4. (e) Mode 5. (f) Mode 6. 


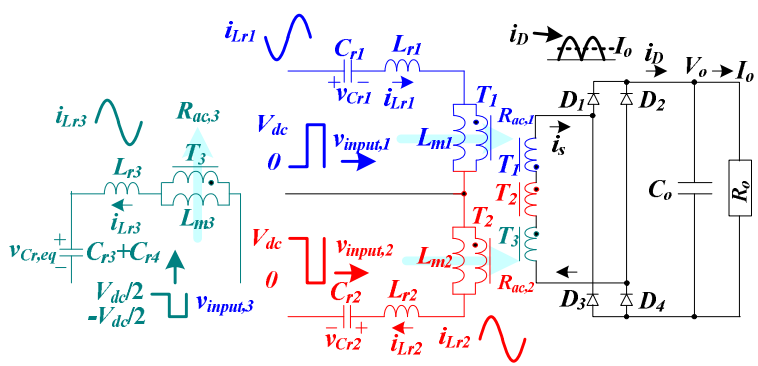

Fig. 4. Equivalent circuit of the proposed converter.

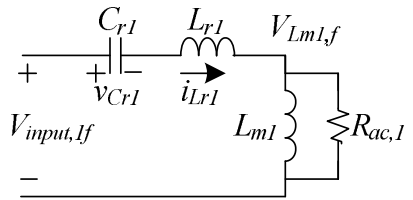

Fig. 5. Equivalent circuit of each resonant tank with fundamental switching frequency.

the energy stored in $L_{r 2}$ and $C_{r 2}$ is transferred to the output load through $Q_{2}, C_{r 2}, L_{r 2}, T_{2}, D_{2}$ and $D_{3}$. Since the switching frequency is less than the series resonant frequency in the proposed converter, the secondary winding current $i_{s}$ will be decreased to zero before switch $Q_{2}$ is turned off. This mode ends at time $t_{4}$ when the secondary side current $i_{s}=0$.

Mode $5\left[t_{4} \leq t<t_{5}\right]$ : This mode starts at $t_{4}$ when $i_{L m 1}=i_{L r 1}$, $i_{L m 2}=i_{L r 2}$ and $i_{L m 3}=i_{L r 3}$. Therefore, the secondary winding current $i_{s}=0$. Diodes $D_{1}-D_{4}$ are all off. Since $Q_{2}$ is still conducting, $C_{r 1}, L_{r 1}$ and $L_{m 1}$ are resonant in circuit 1; $C_{r 2}, L_{r 2}$ and $L_{m 2}$ are resonant in circuit 2; and $C_{r 3}, C_{r 4}, L_{r 3}$ and $L_{m 3}$ are resonant in circuit 3. At time $t_{5}, Q_{2}$ is turned off.

Mode $6\left[t_{5} \leq t<T+t_{0}\right]$ : At $t_{5}, Q_{2}$ is turned off. In this mode, diodes $D_{1}$ and $D_{4}$ are conducting so that the magnetizing voltages $v_{L m 2}=v_{L m 3}=n V_{o} / 3$ and $v_{L m 1}=-n V_{o} / 3$. The magnetizing current $i_{L m 1}$ decreases, and $i_{L m 2}$ and $i_{L m 3}$ increase in this mode. Since the inductor current $i_{L r 1}$ at $t_{5}$ is positive and $i_{L r 2}$ and $i_{L r 3}$ at $t_{5}$ are negative, $C_{o s s 1}$ is discharged and $C_{o s s 2}$ is charged. If the energy stored in $L_{r 1}-L_{r 3}$ is greater than the energy stored in $C_{o s s 1}$ and $C_{o s s 2}$, then $C_{o s s 1}$ can be discharged to zero voltage.

$$
\begin{gathered}
v_{Q 1, d s}(t) \approx V_{i n}+\frac{i_{L r 2}\left(t_{5}\right)+i_{L r 3}\left(t_{5}\right)-i_{L r 1}\left(t_{5}\right)}{2 C_{o s s}}\left(t-t_{5}\right) \\
v_{Q 2, d s}(t) \approx \frac{i_{L r 1}\left(t_{5}\right)-i_{L r 2}\left(t_{5}\right)-i_{L r 3}\left(t_{5}\right)}{2 C_{o s s}}\left(t-t_{5}\right)
\end{gathered}
$$

At time $T+t_{0}$, the drain voltage $v_{Q 1, d s}$ decreases to zero voltage, and the anti-parallel diode of $Q_{1}$ is forward biased. Then the operating modes of the proposed converter in one switching cycle are completed.

\section{CIRCUIT CHARACTERISTICS}

The resonant tank is basically a band-pass filter. The input voltage of the resonant tank is a square wave voltage. If the bandwidth of the band-pass filter is much less than the switching frequency, the harmonics of the input square wave voltage can be neglected at the output of the resonant circuit. A frequency modulation scheme is used to regulate the output voltage. An equivalent circuit of the proposed converter is given in Fig. 4. The duty ratio of each power switch is 0.5 so that the input voltage to the resonant tank is a square waveform. Based on a Fourier series analysis, the input voltages of the resonant tanks are expressed as:

$$
\begin{gathered}
v_{\text {input }, 1}=v_{\text {input }, 2}=\frac{V_{\text {in }}}{2}+\sum_{m=1,3,5 \ldots} \frac{2 V_{\text {in }}}{m \pi} \sin \left(2 \pi m f_{s} t\right) \\
v_{\text {input }, 3}=\sum_{m=1,3,5 \ldots} \frac{2 V_{\text {in }}}{m \pi} \sin \left(2 \pi m f_{s} t\right)
\end{gathered}
$$

There is a DC voltage level $V_{i n} / 2$ on the input voltages $v_{\text {input }, 1}$ and $v_{\text {input }, 2}$. This DC voltage level is blocked by the resonant capacitors $C_{r 1}$ and $C_{r 2}$. Therefore, the input AC voltage components of the three resonant tanks are identical. Since the three resonant tanks have the same circuit components and parameters, only resonant tank 1, as shown in Fig. 5, is discussed to derive the system AC voltage gain. The secondary side current $i_{D}$ is a quasi-sinusoidal current. When the inductor current $i_{L r 1}>i_{L m 1}$, rectifier diodes $D_{2}$ and $D_{3}$ are conducting and $v_{L m 1}=-n V_{o} / 3$. If $i_{L r 1}<i_{L m 1}$, then $v_{L m 1}=n V_{o} / 3$ and rectifier diodes $D_{1}$ and $D_{4}$ are conducting. Generally the capacitor charge/discharge time intervals in modes 3 and 6 and the time intervals in modes 2 and 5 are much less than the time intervals of the series resonant circuit by $L_{r}$ and $C_{r}$ in modes 1 and 4 . Therefore, the magnetizing inductor voltage is a quasi-square waveform and is expressed as:

$$
v_{L m 1}=\sum_{m=1,3,5 \ldots} \frac{4 n V_{o}}{3 m \pi} \sin \left(2 \pi m f_{s} t-\theta_{m}\right)
$$

where $\theta_{m}$ is the phase angle of the $m$-th harmonic frequency. The peak fundamental magnetizing inductor voltage is equal to $\hat{v}_{L m 1, f}=4 n V_{o} /(3 \pi)$. Since the average value of the secondary winding current is equal to the load current, the peak value of the transformer secondary winding current is expressed as:

$$
\hat{i}_{s}=\pi I_{o} / 2
$$

Therefore, the load resistance $R_{o}$ reflected to the transformer primary side is given as [2]:

$$
R_{a c, 1}=R_{a c, 2}=R_{a c, 3}=R_{a c}=\frac{\hat{v}_{L m 1, f}}{\hat{i}_{s 1} / n}=\frac{8 n^{2}}{3 \pi^{2}} R_{o}
$$

The $\mathrm{AC}$ voltage gain of resonant tank 1 , shown in Fig. 5, is derived as:

$$
\left|G_{a c}(f)\right|=\frac{1}{\sqrt{\left[1+k\left(1-\frac{f_{r}^{2}}{f_{s}^{2}}\right)\right]^{2}+Q^{2}\left(\frac{f_{s}}{f_{r}}-\frac{f_{r}}{f_{s}}\right)^{2}}}
$$


where $\quad k=L_{r 1} / L_{m 1}, \quad Q=\sqrt{L_{r 1} / C_{r 1}} / R_{a c, 1}$, $f_{r}=1 /\left(2 \pi \sqrt{L_{r 1} C_{r 1}}\right)$, and $f_{s}$ is the switching frequency. The AC voltage gain at the no-load condition $(Q=0)$ and $f_{s}=\infty$ is given in (11).

$$
\left|G_{a c}(f)\right|_{N L, f_{s}=\infty}=1 /(1+k)
$$

If the minimum DC voltage gain at the maximum input voltage case is greater than the $\mathrm{AC}$ voltage gain at the no-load condition in (11), then the output voltage of the proposed converter can be controlled.

$$
G_{d c, \text { min }}=\frac{n\left(V_{o}+2 V_{f}\right) / 3}{V_{i n, \max } / 2}>\frac{1}{(1+k)}
$$

where $V_{f}$ is the voltage drop across diodes $D_{1}-D_{4}$. From (12), the minimum turns ratio of transformers $T_{1}-T_{3}$ is obtained in (13).

$$
n_{\min }=\frac{3 V_{i n, \max }}{2(1+k)\left(V_{o}+2 V_{f}\right)}
$$

\section{DESIGN EXAMPLE AND EXPERIMENTAL RESULTS}

Based on the system analysis in the previous section, a design example of the proposed converter is presented in this section. A laboratory prototype with a $1.6 \mathrm{~kW}$ rated power was built to verify the effectiveness of the proposed converter. The output voltage and the load current are $400 \mathrm{~V}$ and $4 \mathrm{~A}$. The input voltage range is from $250 \mathrm{~V}$ to $300 \mathrm{~V}$. The selected series resonant frequency $f_{r}$ is $120 \mathrm{kHz}$. The inductance ratio $k=L_{r} / L_{m}$ is selected as 0.2 .

Step 1: Turns ratio of $T_{1}-T_{3}$

The minimum DC gain at the maximum input voltage is designed to be unity (at the series resonant frequency). Therefore, the theoretical turns ratio of $T_{1}-T_{3}$ is given as:

$$
n=\frac{n_{p}}{n_{s}}=\frac{3 V_{i n, \max }}{2\left(V_{o}+2 V_{f}\right)}=\frac{3 \times 300}{2(400+2 \times 1.7)}=1.115
$$

where $V_{f}$ is the voltage drop on diodes $D_{1}-D_{4}$. The actual primary and secondary turns used in the prototype circuit are $n_{p}=33 \mathrm{~T}$ and $n_{s}=30 \mathrm{~T}$.

Step 2: DC voltage gain

The actual minimum and maximum DC gains of the proposed converter are:

$$
\begin{gathered}
G_{d c, \text { min }}=\frac{2\left(V_{o}+2 V_{f}\right) n_{p}}{3 V_{i n, \text { max }} n_{s}}=\frac{2 \times(400+2 \times 1.7) \times 33}{3 \times 300 \times 30}=0.986 \\
G_{d c, \text { max }}=\frac{2\left(V_{o}+2 V_{f}\right) n_{p}}{3 V_{i n, \text { min }} n_{s}}=\frac{2 \times(400+2 \times 1.7) \times 33}{3 \times 250 \times 30}=1.183
\end{gathered}
$$

Step 3: $Q$ value at a full load

Fig. 6 shows the AC voltage gain curves versus the frequency ratio $f_{s} / f_{r}$ with $k=0.2$. In (16), the maximum DC gain is 1.183 . Therefore, the maximum $Q$ at a full load

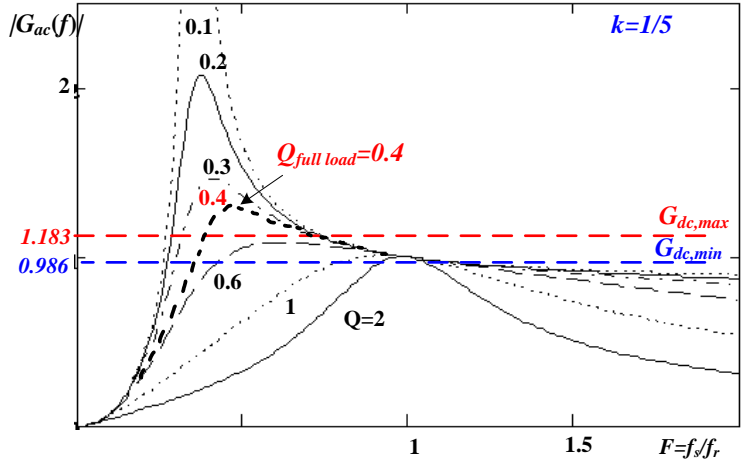

Fig. 6. AC voltage gain and DC voltage gain at different frequency ratio $f_{s} / f_{r}$.

should be less than 0.4, as shown in Fig. 6. Otherwise, no switching frequency exists to regulate the output voltage at the desired voltage level. As a result, the selected $Q$ value at a full load is 0.4 in the prototype.

Step 4: AC equivalent resistance

Based on (9), the AC equivalent resistance $R_{a c}$ at a full load is given as:

$$
R_{a c}=\frac{8 n^{2}}{3 \pi^{2}} R_{o}=\frac{8 \times(33 / 30)^{2}}{3 \times 3.14159^{2}} \times \frac{400}{4}=32.7 \Omega
$$

Step 5: Resonant capacitances and inductances

Since

$$
f_{r}=\frac{1}{2 \pi \sqrt{L_{r} C_{r}}}=120 \mathrm{kHz}
$$

and

$Q=\frac{\sqrt{L_{r} / C_{r}}}{R_{a c}}=0.4$ in (10), the resonant capacitances and inductances are derived as:

$$
\begin{gathered}
L_{r 1}=L_{r 2}=L_{r 3}=L_{r}=\frac{Q R_{a c}}{2 \pi f_{r}}=\frac{0.4 \times 32.7}{2 \pi \times 120000} \approx 17 \mu \mathrm{H} \\
C_{r 1}=C_{r 2}=C_{r}=\frac{1}{4 \pi^{2} L_{r} f_{r}^{2}} \approx 100 \mathrm{nF} \\
C_{r 3}=C_{r 4}=0.5 C_{r}=50 \mathrm{nF}
\end{gathered}
$$

The selected $k=L_{r} / L_{m}=1 / 5$. Therefore, the magnetizing inductances of $T_{1}-T_{3}$ are given as:

$$
L_{m 1}=L_{m 2}=L_{m 3}=L_{r} / k=\frac{17 \mu H}{1 / 5}=85 \mu \mathrm{H}
$$

Step 6: No load condition

From (13), the minimum turns ratio of the transformers at the no-load condition is obtained as:

$$
n_{\min }=\frac{3 V_{i n, \max }}{2(1+k)\left(V_{o}+2 V_{f}\right)}=\frac{3 \times 300}{2(1+0.2)(400+2 \times 1.7)}=0.93
$$

The adopted turns ratio of $T_{1}-T_{3}$ is $n=33 / 30=1.1>n_{\min }$. Therefore, the output voltage of the proposed converter can be controlled at the no-load condition.

Step 7: Power semiconductors

The input maximum voltage is $300 \mathrm{~V}$ and the input DC current is $1600 \mathrm{~W} / 300 \mathrm{~V}=5.3 \mathrm{~A}$. Therefore, MOSFETs 


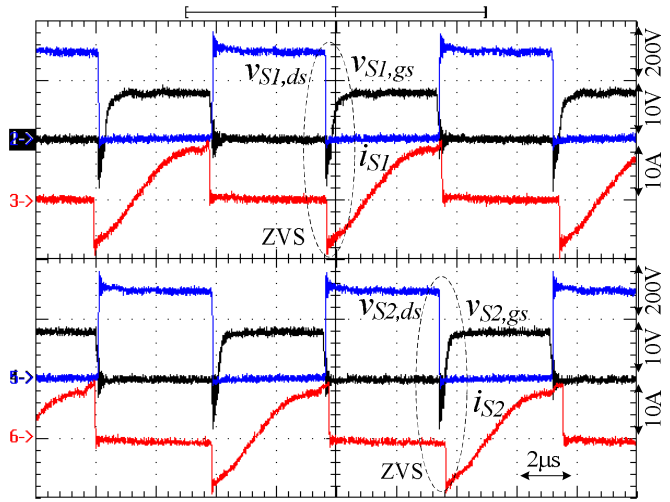

(a)

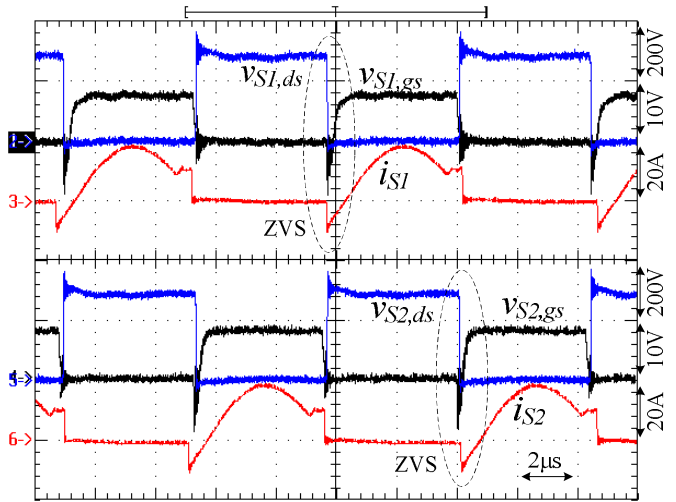

(b)

Fig. 7. Measured gate voltage, drain voltage and switch current of $Q_{1}$ and $Q_{2}$ at (a) $25 \%$ (b) $100 \%$ full load conditions.

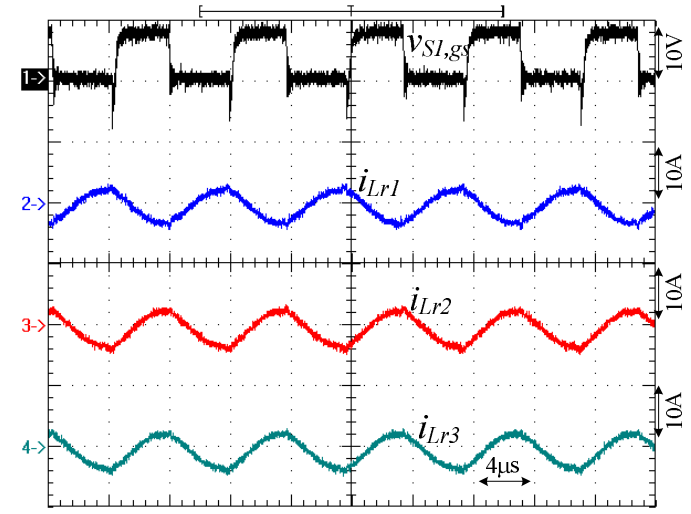

(a)

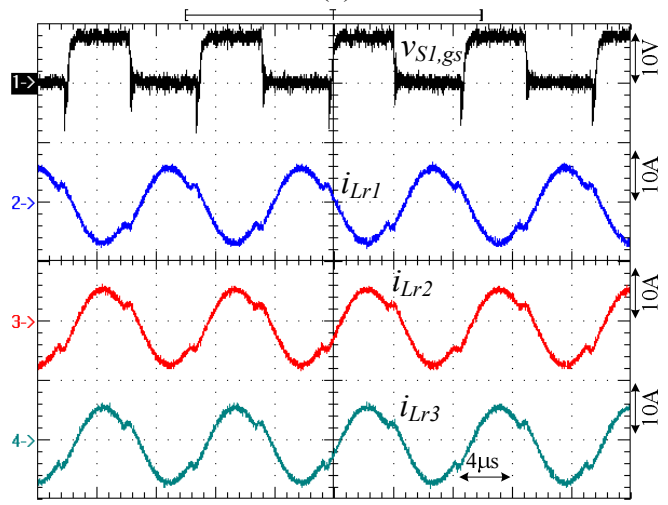

(b)

Fig. 8. Measured gate voltage $v_{Q 1, g s}$, and inductor currents $i_{L r 1}-i_{L r 3}$ at (a) $25 \%$ load (b) full load.

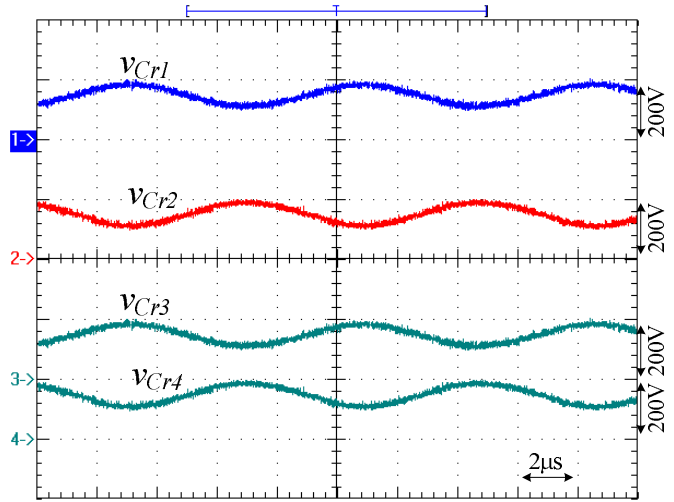

(a)

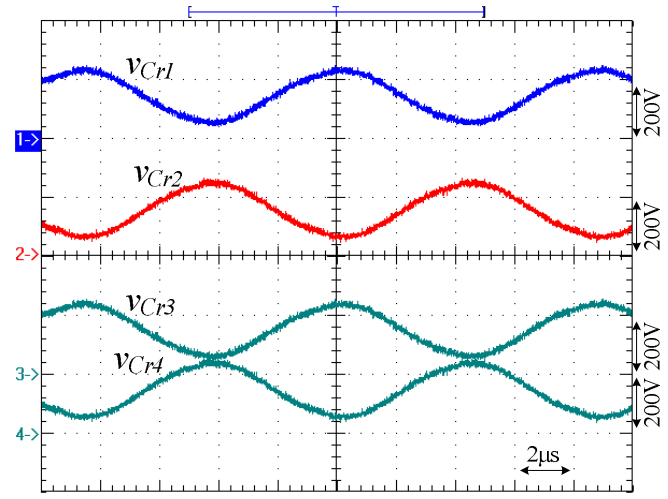

(b)

Fig. 9. Measured resonant capacitor voltages $v_{C r 1}-v_{C r 4}$ at (a) $25 \%$ load (b) full load.

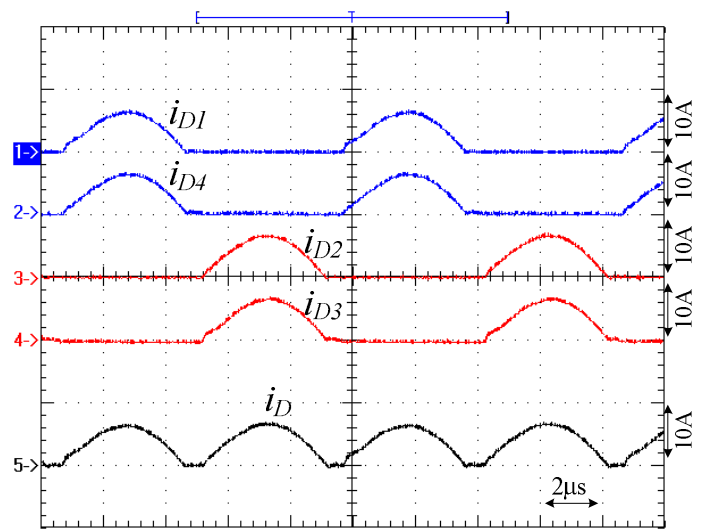

Fig. 10. Measured waveforms of diode currents at full load condition.

(IRFP460) with a $500 \mathrm{~V}$ voltage rating and a $20 \mathrm{~A}$ current rating are used for power switches $Q_{1}$ and $Q_{2}$. The output voltage is $400 \mathrm{~V}$ and the load current is $4 \mathrm{~A}$. FSF10A60 with a $600 \mathrm{~V}$ voltage rating and a $10 \mathrm{~A}$ current rating are used for rectifier diodes $D_{1}-D_{4}$ in the prototype circuit.

Experiments based on a laboratory prototype with the circuit parameters derived in the previous section are provided to verify the effectiveness of the proposed converter. Fig. 7 shows the measured waveforms of the gate voltage, drain voltage and switch current of $Q_{1}$ and $Q_{2}$. Before switches $Q_{1}$ and $Q_{2}$ are turned on, the drain voltage is 


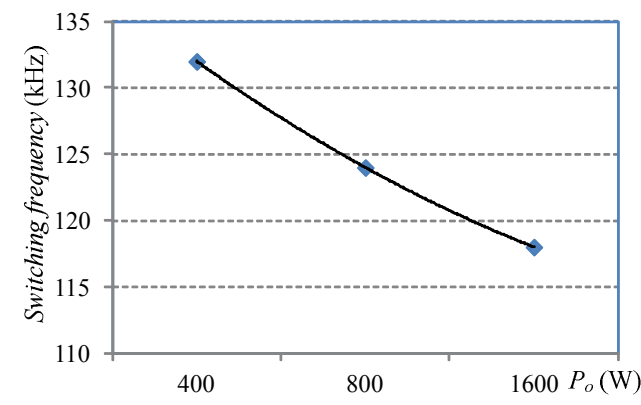

(a)

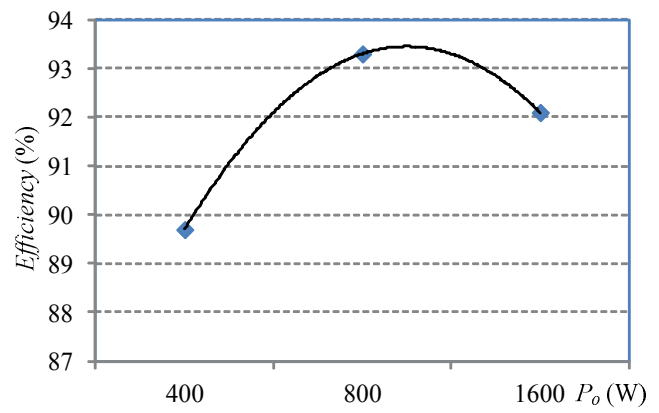

(b)

Fig. 11. Measured switching frequency and efficiency of the proposed converter at different loads. (a) Switching frequency versus load. (b) Efficiency versus load.

decreased to zero. Therefore, switches $Q_{1}$ and $Q_{2}$ are turned on at ZVS. Fig. 8 shows the measured waveforms of the gate voltage $v_{Q 1, g s}$ and the inductor currents $i_{L r 1}-i_{L r 3}$ at the $25 \%$ load and full load conditions. It is clear that the three resonant inductor currents $i_{L r 1}-i_{L r 3}$ are well balanced. Fig. 9 shows the measured resonant capacitor voltages $v_{C r 1}-v_{C r 4}$ at the $25 \%$ load and full load conditions. Fig. 10 shows the measured diode currents at the full load condition. When switch $Q_{1}$ is on, the transformer secondary winding current $i_{s}$ is positive and diodes $D_{1}$ and $D_{4}$ are conducting. If switch $Q_{1}$ is off, the transformer secondary winding current $i_{s}$ is negative and diodes $D_{2}$ and $D_{3}$ are conducting. It is clear that $D_{1}-D_{4}$ are turned off under ZCS. The curves of the switching frequency and efficiency at different loads are shown in Fig. 11. The measured switching frequencies of the proposed converter at $25 \%, 50 \%$ and $100 \%$ loads with a $300 \mathrm{~V}$ input voltage are $132 \mathrm{kHz}, 124 \mathrm{kHz}$ and $118 \mathrm{kHz}$, respectively. The measured circuit efficiencies of the proposed converter at $25 \%, 50 \%$ and $100 \%$ loads with a $300 \mathrm{~V}$ input voltage are $89.7 \% \mathrm{~Hz}, 93.3 \%$ and $92.1 \%$, respectively.

\section{CONCLUSIONS}

A new ZVS converter with three resonant circuits with the same power switches is proposed to achieve the functions of ZVS turn-on of the power switches, ZCS turn-off of the rectifier diodes and less current stress for the primary inductors. As a result, the switching losses on the power switches are reduced, and the reverse recovery current on the rectifier diodes is overcome. Three resonant circuits with the same power switches are adopted at the primary side, and each resonant circuit delivers one-third of the load power to the output side. The secondary windings of the three transformers are connected in series to balance the three primary side currents. A full-wave diode rectifier is adopted at the high voltage side to limit the voltage stress of the rectifier diode at the output voltage. A frequency modulation scheme is adopted to derive the AC voltage conversion ratio. Finally, experimental results are presented to verify the effectiveness of the converter.

\section{ACKNOWLEDGMENT}

This project is supported by the National Science Council of Taiwan under Grant NSC 102-2221-E-224 -022 -MY3.

\section{REFERENCES}

[1] S. Johnson and R. Erickson, "Steady-state analysis and design of the parallel resonant converter," IEEE Trans. Power Electron., Vol. 3, No. 1, pp. 93-104, Jan. 1988.

[2] R. Steigerwald, "A comparison of half bridge resonant converter topologies," in Proc. IEEE IAS, pp. 135-144, 1987.

[3] X. Xie, J. Zhang, Z. Chen, Z. Zhao, and Z. Qian, "Analysis and optimization of LLC resonant converter with a novel over-current protection circuit," IEEE Trans. Power Electron. Vol. 22, No. 2, pp. 435-443, Apr, 2007.

[4] K.-H. Yi, and G.-W. Moon, "Novel two-phase interleaved LLC series-resonant converter using a phase of the resonant capacitor," IEEE Trans. Ind. Electron., Vol. 56, No. 5, pp. 1815-1819, May 2009.

[5] D. Fu, Y. Liu, F. C. Lee, and M. Xu, "A novel driving scheme for synchronous rectifiers in LLC resonant converters," IEEE Trans. Power Electron., Vol. 24, No. 5, pp. 1321-1329, Oct. 2009.

[6] D. Fu, B. Lu and F. C. Lee, "1MHz high efficiency LLC resonant converters with synchronous rectifier," in Proc. IEEE PESC, pp. 2404-2410, 2007.

[7] B.-R. Lin and S.-J. Shen, "Interleaved ZVS resonant converter with a parallel-series connection," Journal of Power Electronics, Vol. 12, No. 4, pp. 528-537, Jul. 2012.

[8] B.-R. Lin and P.-J. Cheng, "New ZVS DC-DC converter with series-connected transformers to balance the output currents," IEEE Trans. Power Electron., Vol. 29, No. 1, pp. 246-255, Jan. 2014.

[9] B. Yang, F. C. Lee, A. J. Zhang, and G. Huang, "LLC resonant converter for front end DC/DC conversion," in Proc. IEEE APEC, Vol. 2, pp. 1108-1112, 2002.

[10] B. R. Lin and S. F. Wu, "Implementation of a series resonant converter with series-parallel transformers," IET Proceeding Power Electronics, Vol. 4, No. 8, pp. 919-926, 2011.

[11] Y. Gu, Z. Lu, L. Hang, Z. Qian, and G. Huang, "Three-level LLC series resonant DC/DC converter," IEEE Trans. Power Electron., Vol. 20, No. 4, pp. 781-789, Jul. 2005. 


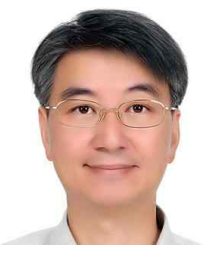

Bor-Ren Lin received his B.S. degree in Electronic Engineering from the National Taiwan University of Science and Technology, Taipei, Taiwan ROC, in 1988, and his M.S. and Ph.D. degrees in Electrical Engineering from the University of Missouri, Columbia, MO, USA, in 1990 and 1993, respectively. From 1991 to 1993, he was a Research Assistant with the Power Electronic Research Center, University of Missouri. Since 1993, he has been with the Department of Electrical Engineering, National Yunlin University of Science and Technology, Douliu, Taiwan ROC, where he is currently a Distinguished Professor. He is an Associate Editor of the Institution of Engineering and Technology Proceedings-Power Electronics and the Journal of Power Electronics. His main research interests include power-factor correction, multilevel converters, active power filters, and soft-switching converters. He has authored more than 200 published technical journal papers in the area of power electronics. Dr. Lin is an Associate Editor of the IEEE Transactions on Industrial Electronics. He was a recipient of Research Excellence Awards in 2004, 2005, 2007 and 2011 from the College of Engineering, National Yunlin University of Science and Technology. He received Best Paper Awards from the 2007 and 2011 IEEE Conference on Industrial Electronics and Applications, the 2007 Taiwan Power Electronics Conference, the 2009 IEEE-Power Electronics and Drive Systems Conference, the 2012 Taiwan Electric Power Engineering Conference, and the 2014 IEEE-International Conference Industrial Technology.

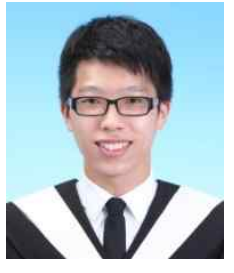

Wei-Jie Lin is currently working toward his M.S. in Electrical Engineering from the National Yunlin University of Science and Technology, Douliu, Taiwan ROC. His current research interests include the design and analysis of power factor correction techniques, switching mode power supplies and soft switching converters. 